\title{
SELECTION OF BREEDING STOCK BY U.S. MEAT GOAT PRODUCERS
}

\author{
NARAYAN NYAUPANE* \\ Samuel Roberts Noble Foundation, Ardmore, Oklahoma \\ JEFFREY GILLESPIE \\ Animal Products and Cost of Production Branch, Market and Trade Economics Division, Economic Research Service, \\ U.S. Department of Agriculture, Washington, D.C. \\ KENNETH MCMILLIN \\ School of Animal Sciences, Louisiana State University Agricultural Center, Baton Rouge, Louisiana \\ ROBERT HARRISON \\ Community and Leadership Development, University of Kentucky, Lexington, Kentucky
}

ISAAC SITIENEI

Department of Agriculture, Texas State University, San Marcos, Texas

\begin{abstract}
Using nationwide survey data, we investigate U.S. meat goat producer preferences and willingness to pay for meat goat breeding stock attributes. Discrete choice experiments were employed, and mixed logit and latent class models were used for analysis. Results showed that producers preferred animals that were highly masculine/feminine, had good structure and soundness, and were of the Boer breed, whereas they preferred fewer animals that were older, of Kiko and Spanish breeds, and priced higher. Significant preference heterogeneity was found among the respondents. Larger-scale producers had greater preference for high masculinity/femininity, good structure and soundness, and Boer bucks.
\end{abstract}

Keywords. Breeding stock, discrete choice experiments, heterogeneity, meat goat, willingness to pay

JEL Classifications. Q11, Q12, Q13, Q19

\section{Introduction}

Major expansion of the U.S. meat goat industry over the past two decades has resulted in an abundance of questions from existing and potential producers about the best goat production methods to use. An important decision faced

This study was part of U.S. Department of Agriculture (USDA), National Institute of Food and Agriculture project 2010-85211-20476, funded through the Agricultural Prosperity for Small and Medium-Sized Farms Agriculture and Food Research Initiative Program. Hatch funds from project LAB94178 were also used to support the project. The views expressed here are not necessarily those of Economic Research Service or the USDA.

*Corresponding author's e-mail: nnyaup1@gmail.com 
by meat goat producers is which animals to purchase for breeding stock. Robust breeding stock can result in higher-quality animals that yield greater farm revenue. However, because the meat goat industry has recently expanded in interest, sparse information has been made available on the economics of meat goat production in general and breeding stock in particular. A wide range of perceptions exists among producers as to the relative strengths and weaknesses of various meat goat breeds. We are unaware of previous research that has objectively examined producer preferences for specific meat goat breeding stock attributes and the values placed on those attributes. Knowledge of these preferences could provide information to producers on which meat goat attributes are most valued by their peers, lending insight into the types of animals that are most valuable.

From 1987 to 2012, the number of U.S. meat goat farms increased from 29,354 to 100,910, and the U.S. meat goat inventory increased from 415,196 to 2,053,228 (U.S. Department of Agriculture, Animal and Plant Health Inspection Service, Veterinary Services [USDA-APHIS-VS], 2005; USDA, National Agricultural Statistics Service [NASS], 2014). This expansion occurred for a number of reasons. U.S. goat meat demand increased primarily in response to a surging immigrant population from goat meat-consuming countries in Central and South America, Africa, and Asia. Furthermore, other industry developments have encouraged meat goat production expansion, including (1) establishment of meat goat producer organizations such as the American Meat Goat Association (1992) and the American Boer Goat Association (1993); (2) repeal of the Wool Act of 1954 (1993), which caused Angora goat producers to consider alternative goat production enterprises; and (3) the U.S. tobacco settlement (1998), which caused tobacco farmers to search for alternative enterprises that would fit on relatively small acreage (Shurley and Craddock, 2005). Though meat goat production has increased dramatically in recent years, total import of frozen goat meat has also continued to rise as it was 1,749 metric tons in 1991, 8,462 metric tons in 2003, and 15,752 metric tons in 2011 (Stanton, 2012). On the other hand, the U.S. foreign-born population increased from 9.7 million in 1960 to 31.3 million in 2000 and to 41.3 million in 2013 (Pew Research Center, 2015). The percentage of immigrants coming from different parts of the world has also been shifting over the years. In 1966, immigrants coming from Europe and Canada comprised $84 \%$ of the total, which dropped to $14 \%$ in 2013 , whereas during the same period, immigrants from goat meatconsuming areas such as Mexico, South and East Asia, and other Latin American countries increased from $6 \%, 4 \%$, and $4 \%$ to $28 \%, 26 \%$, and $24 \%$, respectively (Pew Research Center, 2015). This suggests there is an opportunity for further expansion of meat goat production if new farms can compete with the relatively low cost of goat meat imports, especially those from Australia. Considering the recent expansion, reasons for expansion, and expectations that the industry will either continue to expand or at least maintain current production, the provision 
of basic economic information that will assist meat goat farmers in making betterinformed decisions is warranted.

The quality and quantity of meat goats produced on a farm depend to a greater degree on breeding stock (Casey and Webb, 2010). Purchasing breeding stock requires thoughtful consideration from producers as significant investment is required in developing a herd, with breeding stock prices commonly ranging from $\$ 200$ to $\$ 1,500$ per animal depending on gender and quality attributes. Several studies have addressed producer preferences for breeding stock in the cattle industry (Ouma, Abdulai, and Drucker, 2007; Ruto, Garrod, and Scarpa, 2008; Sy et al., 1997; Tano et al., 2003), but we are aware of no previous studies that have addressed this issue for the meat goat industry. The objectives of this study are to determine the following: (1) producer preferences for the attributes of meat goat breeding bucks and does, (2) the degree of heterogeneity of producer preferences for meat goat breeding stock attributes, (3) producer willingness-to-pay (WTP) for selected meat goat breeding stock attributes, and (4) the most preferred bucks and does and their relative values. We use discrete choice experiments (DCEs) to address these objectives.

\subsection{Studies Examining Farmer Preferences for Animal Attributes}

Sy et al. (1997) studied producer preferences for cattle characteristics in Manitoba, Canada, among three production segments: purebred breeders, commercial cow-calf operators, and cattle feeders. Using ratings-based conjoint analysis, they found different preferences for animal attributes by segment. A similar study examined producer preferences for cattle attributes in West Africa where literacy was low and commercial production was not yet developed (Tano et al., 2003). Results suggested that preferred attributes for bulls were fitness to traction, disease resistance, and fertility, and those for cows were reproductive performance, disease resistance, and feeding ease. A choice-based conjoint study of Kenyan and Ethiopian cattle producers suggested that production environment and production system were the major factors influencing cattleowners' preferences for animal attributes (Ouma, Abdulai, and Drucker, 2007). Results suggested that production environment and production system were the major factors influencing cattle owners' preferences for animal attributes. They further argued that an understanding of preference heterogeneity among livestock producers would help in designing better breeding strategies for specific production systems. Ruto, Garrod, and Scarpa (2008) evaluated buyers' preferences of indigenous cattle breeds in Kenya using a choice experiment approach and found that there were at least three distinct classes of buyers, most of which preferred exotic over indigenous breeds.

\subsection{Why Discrete Choice Experiments?}

Although many studies similar to ours have used the term "conjoint analysis" for the methodologies they used, we refer to the method as DCE because the basis 
of random utility and economic demand theories that are traditionally used in conjoint analysis are more consistent with DCE (Louviere, Flynn, and Carson, 2010). In agriculture, DCEs are used when determining the likability of products and the WTP for product attributes. In contrast to the revealed preference method where observations are made based on actual market situations, the stated preference method is advantageous in that it provides a hypothetical market scenario and allows the study of consumer preferences for new products and/or unique product attributes that have not yet been introduced into the market and for which sufficient transaction data are not available.

In general, estimation of the marginal contributions of specific input attributes to overall farm performance can be conducted using two major approaches: (1) the production function approach, where marginal value products can be derived for each of the given attributes, and (2) the consumer demand approach, which investigates how consumer demand differs based on the utilities derived from products with differing attributes (Sy et al., 1997). A major advantage of the consumer demand approach over the production function approach, according to Sy et al. (1997), is that managerial skills can be captured by including demographic variables. We choose the consumer demand approach with an assumption that meat goat producers (considered as consumers when they purchase breeding stock) are expected to select animals that lead to maximum utility.

Coffey (2006) suggested that the meat goat breeding stock purchase decision generally depends largely on factors such as the scale of projected production, the types of meat goats one plans to produce, intended market and consumer preferences, expected market price, the cost of maintaining bucks and does, and others. Although production intentions and expected returns are likely to be major considerations, personal preferences of producers for raising certain types of animals may also be important. The availability of animals and their suitability for local conditions can also significantly affect these decisions (Coffey, 2006). For instance, Kiko goats have high resistance to parasites and lower hoof problems (Coffey, 2006; Wade, 2004), so they may be more preferred in areas with higher incidence of those problems.

Utility derived by meat goat producers by selecting animals with particular attributes is assumed to be economic in nature; for instance, producers are expected to select animals that generate more animals/meat with certain qualities that have higher market value, thereby resulting in greater revenue. Utility can be separated into two parts: the deterministic $\left(V_{n A}\right)$ and the random or stochastic $\left(\varepsilon_{n A}\right)$ parts (Ouma, Abdulai, and Drucker, 2007). It can be represented as $U_{n A}$ :

$$
U_{n A}=V_{n A}+\varepsilon_{n A} .
$$

The basic assumption in choice experiments is that an individual $(n)$ would select alternative $A$ over another alternative $(B)$ if and only if the utility received from consuming $A$ were greater than or at least equal to that from $B$. This can 
be represented as

$$
U_{n A} \geq U_{n B},
$$

where $U_{n A}$ and $U_{n B}$ are utilities received from consuming alternatives $A$ and $B$, respectively.

Utility received from consuming an alternative can be represented as the vector of attributes for that alternative:

$$
U_{n A}=U\left(X_{n A}\right),
$$

where $X_{n A}$ represents the vector of attributes of the alternative $A$ (Ouma, Abdulai, and Drucker, 2007). The probability of individual $n$ selecting $A$ over other choice alternatives can be represented as

$$
P(A)=\operatorname{Prob}\left\{V_{n A}+\varepsilon_{n A} \geq V_{n j}+\varepsilon_{n j}\right\} ; A \neq j, \forall j \epsilon k,
$$

where $j$ is a finite set of alternatives and $k$ is a given choice set situation (Ouma, Abdulai, and Drucker, 2007).

In this study, the utility each producer receives from selecting a buck or doe over a set of alternatives $j$ in choice situation $t$ can be represented as the following utility function:

$$
U_{n j t}=\beta_{n} x_{n j t}+\varepsilon_{n j t},
$$

where $x_{n j t}$ represents the buck/doe attributes and socioeconomic characteristics of meat goat producers, $\varepsilon_{n j t}$ represents identically and independently distributed random errors, and $\beta_{n}$ is a coefficient vector that depends on the density function.

\section{Data and Methods}

\subsection{Identifying Attributes to Be Included in the Discrete Choice Experiments}

To identify attributes meat goat producers generally consider when purchasing breeding stock, 15 meat goat producers near Baton Rouge, Louisiana, were emailed and asked about their primary considerations when selecting breeding stock. Seven replied. From the list of suggested attributes, 10 most common attributes were selected for further evaluation by a group of industry experts, animal scientists, and agricultural economists who work closely with the meat goat industry. Attributes that most of the producers considered important when selecting bucks included head size, animal strength, fertility, and shape and size of the scrotum. For does, head size, fertility, and udder characteristics were of importance. After discussion with industry experts and animal scientists, those attributes were collectively represented as Masculinity and Femininity for bucks and does, respectively. ${ }^{1}$ Therefore, a buck with high masculinity was defined to

1 Although all of these attributes were uniquely important, the reason for aggregating them was to limit the size of the fractional-factorial design so that each of the hypothetical animal profiles could be 
mean that he is powerful, has a wide/strong head, and has a smooth scrotum. Likewise, a doe with high femininity was defined to mean that she has a round and feminine head and has a sound udder.

Other common attributes included the shape and size of the animal, particularly the bone-to-muscle ratio, surface of the backbone, and horn spacing, which were collectively termed as Structure and Soundness. An animal with good structure and soundness was defined as one with good bone/muscle ratio, and healthy. ${ }^{2}$ Age was included because it is considered as a major determinant of a breeding animal's productive life. Age levels of $\leq 2$ years and $>2$ years were included. Three commonly used meat goat Breeds (Boer, Kiko, and Spanish) were included with the rest captured as "Other." To estimate the value given by producers for each of the attributes, breeding stock Price ${ }^{3}$ was considered. Price levels identified for bucks were $\$ 300, \$ 700, \$ 1,100$, and $\$ 1,500$; and for does, $\$ 200, \$ 550, \$ 900$, and $\$ 1,250$. Table 1 provides the list of attributes and levels used in this study, as well as the percentages of respondents preferring different attribute levels.

\subsection{Designing Discrete Choice Experiment Questions}

A DCE design is balanced when all levels of an attribute are used an equal number of times in the survey. A balanced design minimizes the variance and covariance, as the intercept is orthogonal to each effect (Kuhfeld, Tobias, and Garratt, 2010). Minimizing the variance and covariance of the parameter estimates is the primary consideration in creating a design, whereas maintaining orthogonality is secondary. When a design is balanced and orthogonal, it is optimal (Kuhfeld, Tobias, and Garratt, 2010). Kuhfeld, Tobias, and Garratt (2010) argued that the best designs are created when computerized search is combined with human design skills.

incorporated in the survey. In other words, there were several attributes suggested by the producers that were important, but using them directly in the conjoint design would have made the total number of hypothetical animal profiles significantly larger, thereby limiting our ability to question the respondents without imposing fatigue on them.

2 Verbal descriptions of attributes were used over pictorial representation because of three primary reasons. First, it was fairly impossible for us to find different sets of "typical” pictures of high and how masculinity/femininity (and also with other combinations of attributes). Second, the background, breeds, size, and so forth of the goats used in the pictures would have resulted in some bias among producers. For instance, a goat picture with high masculinity may not be perceived as "High Masculine" by some respondents as their impressions may differ with other qualities of the picture. Third, significantly higher number of pictures would have been required to describe each scenario, which would have further complicated the study. Instead, verbal descriptions of these critically important attributes were used to provide a uniform base for all the respondents.

3 Several farm websites that advertised breeding stock animals (both buck and doe) for sale were visited, and the lowest and highest prices listed for various breeding stock were considered as two extreme levels for the price attribute. The other two middle price levels were created based on equal intervals from both ends. 
Table 1. Descriptive Statistics of the Attributes and Levels used in the Study

\begin{tabular}{|c|c|c|c|}
\hline Attributes, Buck/Doe & Levels, Buck/Doe & $\begin{array}{l}\text { Percentage } \\
\text { (standard deviation) } \\
\text { of Producers } \\
\text { Selecting Bucks } \\
\text { with These } \\
\text { Attribute Levels }\end{array}$ & $\begin{array}{l}\text { Percentage } \\
\text { (standard deviation) } \\
\text { of Producers } \\
\text { Selecting Does with } \\
\text { These Attribute } \\
\text { Levels }\end{array}$ \\
\hline Masculinity/femininity & $\begin{array}{l}\text { High } \\
\text { Low }\end{array}$ & $68.47(46.49)$ & $71.23(45.42)$ \\
\hline Structure and soundness & $\begin{array}{l}\text { Good } \\
\text { Poor }\end{array}$ & $83.57(37.07)$ & $48.63(50.15)$ \\
\hline Age & $\begin{array}{l}\leq 2 \text { years } \\
>2 \text { years }\end{array}$ & $43.11(49.55)$ & $17.81(38.39)$ \\
\hline Breed & $\begin{array}{l}\text { Kiko } \\
\text { Spanish } \\
\text { Boer } \\
\text { Others }\end{array}$ & $\begin{array}{r}30.76(46.18) \\
22.60(41.85) \\
37.60(48.46) \\
9.04(28.69)\end{array}$ & $\begin{array}{c}10.96(31.35) \\
71.23(45.42) \\
17.81(38.39) \\
0\end{array}$ \\
\hline Price & $\begin{array}{l}\$ 1,500 / \$ 1,250 \\
\$ 1,100 / \$ 900 \\
\$ 700 / \$ 550 \\
\$ 300 / \$ 200\end{array}$ & $\$ 896.69(422.48)$ & $\$ 1,031.85(236.63)$ \\
\hline
\end{tabular}

Our design included five attributes with three attributes having two levels each and the other two having four levels each. This resulted in $2 \times 2 \times 2 \times 4 \times 4=$ 128 total hypothetical animal profiles. It would be infeasible to incorporate all 128 profiles into one study as survey respondent fatigue would be of concern. Thus, a balanced and orthogonal fractional factorial design was used (Kuhfeld, Tobias, and Garratt, 2010). For both bucks and does, 16 computer-generated hypothetical animal profiles were selected, and from those, 8 choice sets were manually constructed to form a DCE in such a way that each pair differed for the maximum number of levels possible (sample choice sets are provided in Appendix A). The sample of farmers to be surveyed was divided into two groups, one group receiving the survey with DCE questions for bucks and the other receiving the questions for does. The remaining survey questions were the same. The reason for splitting the population was concern about respondent fatigue, where including both bucks and does would have required respondents to compare $16 \times 2=32$ hypothetical animal profiles (16 choice sets).

Brief descriptions of some of the attributes and their levels were provided if we believed clarification was needed. These descriptions appeared in the introductory verbiage to the DCE section of the survey as follows: (1) Masculinity: We mean that the buck is powerful, has a wide/strong head, and has a smooth scrotum. (2) Femininity: We mean that the doe has a round and feminine head and has a sound udder. (3) Structure and Soundness: We mean the buck/doe has good bone/muscle structure, and is healthy. (4) Others: We 
mean breeds other than Boer, Spanish, and Kiko. Other than the characteristics provided, respondents were asked to imagine that the animals were identical. A question for each choice set was asked as follows: "Which doe would you buy if these were the only does available in the marketplace?" Possible choices included "Doe A," "Doe B," and "Neither" for does. The questions were similarly worded for bucks.

\subsection{Mailing the Questionnaire}

Using Dillman, Smyth, and Christian (2009) as a guide, questionnaires were sent to U.S. meat goat producers via first-class mail during late summer-early fall 2012. The producer list was developed from Internet addresses of meat goat producers. These producers were advertising via the Internet or were included on posted lists as members of meat goat associations. The first round of mailing included a cover letter, the 10-page questionnaire, a complementary pen, and a postage-paid return envelope, followed by a postcard reminder 2 weeks later. The third mailing included a new cover letter, questionnaire, and return envelope 2 weeks after the first postcard reminder. This was also followed by a second postcard reminder 2 weeks later. Thus, a total of four contacts were made. Of 1,600 surveys sent, 584 usable responses were obtained, and 242 additional ones were removed because the farmers either did not produce meat goats during 2011 or the surveys were undeliverable (bad addresses). Thus, the adjusted response rate was $43 \%$.

\subsection{Representativeness of the Sample Population}

The U.S. Census of Agriculture provides a count of U.S. livestock farms and includes farms with as few as 1 goat. Our study, on the other hand, is a sample representing "commercial meat-goat producers." The national average for the total number of meat and other goats per farm as estimated by the 2012 Census of Agriculture (USDA-NASS, 2014) was 20, whereas our sample farms had 62 goats, including 17 goats for hair, dairy, and other purposes. This indicates that farms in our sample population were relatively larger-scale than the average agricultural census farm. However, several things should be considered before concluding our sample farms were not representative of national average farms. First, to be considered in the agricultural census, a farm must have $\geq 1$ goat in inventory and total annual farm sales of $\geq \$ 1,000$. A majority of U.S. meat goat farms $(52.4 \%)$ had $<10$ goats according to the 2007 Census of Agriculture, and, of those farms having $<10$ goats, $72.4 \%$ indicated that their focus was not primarily commercial, but "other" such as livestock shows, pack animals, pets, and brush control (USDA-APHIS-VS, 2011). On the other hand, only $4.9 \%$ of the farms that had 100-499 goats focused on "other" functions, indicating the larger farms were less likely to be focused on "other" functions.

It is evident that farm size serves as a clear indicator for determining whether the farm was "commercial." Thus, we argue that the 2012 Census of Agriculture 
(USDA-NASS, 2014) average of 20 goats per farm cannot be considered to be representative of commercial meat goat production, whereas our sample $(62$ goats) behaved more consistently as commercial producers. Producers in our sample were members of meat goat associations and/or were advertising their products via the Internet. All but seven states in the United States (AK, CT, HI, MT, NV, RI, and WY) were represented in our sample. These seven states accounted for $<2 \%$ of U.S. meat goat farms in 2007 (USDA-NASS, 2009).

\subsection{Econometric Methods}

The mixed logit model with latent classes (Hole, 2007; Pacifico and Yoo, 2012) is used in this study. The mixed logit model is a modification of the more commonly used multinomial logit model (Greene, 2008, p. 851; Train, 2009). The mixed logit model has advantages over the multinomial logit because it (1) is more flexible and incorporates random utility models, (2) does not require the independence of irrelevant alternatives (IIA) assumption and allows taste parameters to vary randomly, (3) accommodates unrestricted substitution patterns, and (4) allows for correlation of unobserved factors over repeated choice situations (Train, 2009). Choice probabilities in the mixed logit are expressed as

$$
P_{n i}=\int L_{n i}(\beta) f(\beta) d \beta,
$$

where $f(\beta)$ is a density function and $L_{n i}(\beta)$ is the logit probability evaluated at parameter $\beta$ (Hole, 2007):

$$
L_{n i}(\beta)=\frac{e^{V_{n i}(\beta)}}{\sum_{j=1}^{J} e^{V_{n j}(\beta)}} .
$$

Function $V_{n i}(\beta)$ is observed utility that depends on $\beta$. If observed utility is linear in $\beta$, then $V_{n i}(\beta)=\beta^{\prime} x_{n i}$ and the mixed logit probability can be expressed as

$$
P_{n i}=\int \frac{e^{\beta^{\prime} x_{n i}}}{\sum_{j} e^{\beta^{\prime} x_{n j}}} f(\beta) d \beta .
$$

The mixed logit is a weighted average of logit models evaluated at different $\beta$ 's, where the density function, $f(\beta)$, provides weights by acting as a mixing distribution. In this study, initially the model was estimated using 50 Halton draws, whereas in the final model, we used 500 Halton draws for simulation. Time required to run the model and estimation accuracy increase with the number of draws used (Hole, 2007). Further details on Halton sequences and random draws for simulation-based integration can be found in Greene (2008) and Train (2000, 2009).

Boxall and Adamowicz (2002) showed that the mixed logit model can estimate heterogeneous preferences by allowing model parameters to vary 
over respondents. The model, however, cannot explicitly reveal the sources of heterogeneity. Socioeconomic characteristics of respondents are common sources of heterogeneity in most cases. As discussed by Boxall and Adamowicz (2002), possible approaches to deal with this problem have been to (1) conduct multivariate cluster analysis of sociodemographic characteristics and estimate individual choice models for each of the homogeneous segments (Salomon and Ben-Akiva, 1983) or (2) parameterize scales in binary logit models (Cameron and Englin, 1997). For both approaches, a common problem is that a priori knowledge of the sources of heterogeneity is required. Sociodemographics may not be the only sources of heterogeneity; therefore, an approach that can incorporate all possible sources of heterogeneity is needed. Latent class models are a possible solution. Previous studies have used latent class models (Ouma, Abdulai, and Drucker, 2007; Ruto, Garrod, and Scarpa, 2008) in estimating preference heterogeneity.

Using the latent class model, the population is intrinsically divided into different classes. Preference is assumed to be homogeneous within each class, whereas it is heterogeneous across classes. An individual's belonging to a class is probabilistic in nature. The number of classes used is, in a sense, endogenously determined (Greene and Hensher, 2003). The researcher chooses the optimum number of classes based on the Akaike information criterion (AIC) and the Bayesian information criterion (BIC), with the optimum number of classes decided based on the lowest value of the AIC/BIC (Pacifico and Yoo, 2012). Researchers do not specify the nature of the classes, but only the important determinants for classes in the model. Based on the homogeneity among individuals, significance of the variables is observed, ultimately determining the nature of each class. As described in Ruto, Garrod, and Scarpa (2008), the joint logit probability that individual $n$ associated with latent class $l$ chooses a set of alternatives $\left(T_{n}\right)$ can be represented as

$$
P_{(T n \mid l)}=\prod_{t=1}^{T_{n}} \frac{\exp \left(\beta_{l}^{\prime} x_{n i t}\right)}{\sum_{j=1}^{J} \exp \left(\beta_{l}^{\prime} x_{n j t}\right)},
$$

where $x_{\text {nit }}$ is a vector of alternative specific attributes, $\beta_{l}^{\prime}$ is a vector of classspecific parameters, and $t$ is the number of choice situations faced by an individual. The class-specific parameter vector $\left(\beta_{l}^{\prime}\right)$ captures the heterogeneity of preferences that different segments of U.S. meat goat producers might hold (Pacifico and Yoo, 2012).

Because the classes are latent such that an individual falling into one class cannot be described directly, the probability of an individual being associated with a class can be estimated using the multinomial logit model as

$$
P(l)=\frac{\exp \left(\theta_{l}^{\prime} Z_{n}\right)}{\sum_{l}^{L} \exp \left(\theta_{l}^{\prime} Z_{n}\right)},
$$


where $Z_{n}$ is a vector of variables that enter the model of class membership and $\theta_{l}^{\prime}(l=1,2, \ldots ., L)$ denotes the class-specific parameters (Ruto, Garrod, and Scarpa, 2008). This model does not impose the IIA assumption. Parameters estimated using this model would form the expected probability that individual $n$ would choose a buck/doe of particular attributes, given the person belongs to a particular class membership. Estimation of these models was conducted using Stata modules developed by Pacifico and Yoo (2012).

Producer WTP for an attribute $a$ of a breeding buck/doe can be estimated as the negative ratio of the attribute coefficient and price coefficient as follows:

$$
W T P_{a}=-\frac{\beta_{a}}{\beta p}
$$

where $\beta_{a}$ and $\beta_{p}$ are the coefficients of the attribute $a$ and price, respectively (Ruto, Garrod, and Scarpa, 2008).

\subsection{Variables Used in the Study}

Table 1 shows the attributes and levels used in the study. Consistent with findings by previous studies that strong fertility and reproductive performance is preferred (Ouma, Abdulai, and Drucker, 2007; Tano et al., 2003), meat goat producers were expected to have positive preferences for higher levels of Masculinity and Femininity for bucks and does, respectively, in breeding stock selection. Structure and Soundness shows the animal's overall health and body confirmation, with higher levels generally expected to correlate with sound genetics and greater productive potential and therefore expected to be positively preferred. Older breeding stock generally has less remaining productive life; therefore younger animals are expected to be preferred. Breed preferences are investigated. Lower prices are expected to be preferred.

To determine preference heterogeneity, farm descriptors, producer demographics, and regional variables were incorporated into the latent class model. Number Goats is the total number of meat goats on the farm, representing farm size. Percentage of meat goats sold for slaughter or as meat as opposed to sales for breeding stock, show, or other purposes was represented as a continuous variable, Percent Sale Slaughter. Producer demographics were represented by Age and Bachelor, where Age is a continuous variable representing producer age ranging in 15-year intervals, and Bachelor is a dummy variable indicating whether a producer held at least a bachelor's degree. Percentage of annual net farm income derived from the goat operation was included as Farm Income Goat, a continuous variable ranging from 1 to 5 , each in $20 \%$ intervals.

Diversity of preferences by geographic region was captured by incorporating regional variables: Southeast, Northeast, Midwest, West, and Texas/Oklahoma, indicating the farms were located in those regions, as defined in Table 2. 
Table 2. Descriptive Statistics of the Variables Used in the Latent Class Models

\begin{tabular}{|c|c|c|}
\hline Variables & Description & Mean \\
\hline Number Goats & Total number of meat goats on the farm & 61.57 \\
\hline Boer & Total number of Boer goats on the farm & 29.90 \\
\hline Kiko & Total number of Kiko goats on the farm & 13.56 \\
\hline Spanish & Total number of Spanish goats on the farm & 1.52 \\
\hline Others & Total number of Other goats on the farm & 16.59 \\
\hline Myotonic & Total number of Myotonic goats on the farm & 0.64 \\
\hline Savanna & Total number of Savanna goats on the farm & 0.32 \\
\hline Pygmy & Total number of Pygmy goats on the farm & 0.29 \\
\hline Mixed & Total number of Mixed goats on the farm & 11.95 \\
\hline Angora & Total number of Angora goats on the farm & 0.97 \\
\hline Cashmere & Total number of Cashmere goats on the farm & 0.26 \\
\hline Others & Total number of Other goats on the farm & 2.16 \\
\hline Percent Sale Slaughter & Percentage of goats sold for slaughter or as meat & 44.61 \\
\hline Age & $\begin{array}{l}\text { Producer age (years): } \leq 30(\mathrm{a}), 31-45(\mathrm{~b}), 46-60(\mathrm{c}), 61-75(\mathrm{~d}) \\
\quad \geq 76(\mathrm{e})\end{array}$ & 51.91 \\
\hline Bachelor & Binary variable $=1$ if producer holds a bachelor's degree & 0.45 \\
\hline Farm Income Goat & $\begin{array}{l}\text { Percentage of annual net farm income derived from goat } \\
\text { operation, } 20 \% \text { intervals }\end{array}$ & 39.86 \\
\hline Southeast & $\begin{array}{l}\text { Producers located in states AL, AR, FL, GA, KY, LA, MS, NC, } \\
\text { SC, TN, VA, and WV }\end{array}$ & 0.36 \\
\hline Northeast & $\begin{array}{l}\text { Producers located in states CT, DE, MA, MD, ME, NH, NJ, NY, } \\
\text { PA, RI, and VT }\end{array}$ & 0.07 \\
\hline Midwest & $\begin{array}{l}\text { Producers located in states KS, IA, IL, IN, MI, MN, MO, ND, } \\
\text { NE, OH, SD, and WI }\end{array}$ & 0.37 \\
\hline West & $\begin{array}{l}\text { Producers located in states AK, AZ, CA, CO, HI, ID, MT, NM, } \\
\text { NV, OR, UT, WA, and WY }\end{array}$ & 0.09 \\
\hline Texas/Oklahoma & Producers located in states TX and OK & 0.11 \\
\hline
\end{tabular}

\section{Results}

Although conditional logit and the mixed logit models could be interchangeably used in this type of study, we selected the mixed logit model so that we could determine the heterogeneity of preferences across different types of producers and production systems. For both the buck and doe models, likelihood ratio test results suggest at the $P \leq 0.01$ level the superiority of the mixed logit models. Table 2 shows the descriptive statistics of the variables used in the latent class model.

\subsection{Results from Mixed Logit Models}

Table 3 presents the mixed logit simulated maximum likelihood estimates for bucks and does. All of the mean coefficient values were statistically significant at $P \leq 0.10$ except for Femininity in the doe model. All signs for preference were consistent with expectations. Animals less likely to be preferred as breeding stock were older, had higher purchase prices, and were of the Kiko and/or Spanish 
Table 3. Simulated Maximum Likelihood Estimates from the Mixed Logit Model

\begin{tabular}{|c|c|c|c|}
\hline Buck Attributes & $\begin{array}{l}\text { Mean Coefficient } \\
\text { (standard error) }\end{array}$ & $\begin{array}{l}\text { Standard } \\
\text { Deviation } \\
\text { (standard error) }\end{array}$ & $\begin{array}{l}\text { Attribute Levels (\% } \\
\text { share of population } \\
\text { preferred) }\end{array}$ \\
\hline Masculinity & $0.6277^{* * *}(0.0940)$ & $-0.0766(0.2228)$ & High (99) \\
\hline Structure and soundness & $2.0909^{* * *}(0.1144)$ & $-0.4747^{* *}(0.2192)$ & Good (99) \\
\hline Age & $-1.0224^{* * *}(0.0849)$ & $0.0065(0.2135)$ & $>2$ years $(1)$ \\
\hline Kiko & $-1.2355^{* * *}(0.1882)$ & $2.0069^{* * *}(0.2187)$ & Kiko (27) \\
\hline Boer & $0.2586^{* *}(0.1117)$ & $0.8595^{* * *}(0.1683)$ & Boer (62) \\
\hline Spanish & $-1.0792^{* * *}(0.1680)$ & $-0.9284^{* * *}(0.2100)$ & Spanish (12) \\
\hline Price & $-0.0020^{* * *}(0.0001)$ & $-0.0012^{* * *}(0.0001)$ & Lower price (96) \\
\hline Observations & 7,242 & & \\
\hline Likelihood ratio test & $334.54 * * *$ & & \\
\hline $\begin{array}{l}\text { Simulated log likelihood } \\
\text { at convergence }\end{array}$ & $-1,885.15$ & & \\
\hline \multicolumn{4}{|l|}{ Doe Attributes } \\
\hline Femininity & $0.1128(0.1057)$ & $-0.3955^{*}(0.2223)$ & \\
\hline Structure and soundness & $2.6300^{* * *}(0.1418)$ & $0.5698^{* *}(0.2245)$ & Good (99) \\
\hline Age & $-0.7446^{* * *}(0.0941)$ & $0.1420(0.2645)$ & $>2$ years $(1)$ \\
\hline Kiko & $-0.9353^{* * *}(0.1988)$ & $2.1619^{* * *}(0.2340)$ & Kiko (33) \\
\hline Boer & $0.4295^{* * *}(0.1368)$ & $-1.1309^{* * *}(0.1892)$ & Boer (64) \\
\hline Spanish & $-0.8252^{* * *}(0.1777)$ & $-1.2682^{* * *}(0.2262)$ & Spanish (26) \\
\hline Price & $-0.0030^{* * *}(0.0002)$ & $0.0017^{* * *}(0.0002)$ & Lower price (96) \\
\hline Observations & 6,312 & & \\
\hline Likelihood ratio test & $366.44 * * *$ & & \\
\hline $\begin{array}{l}\text { Simulated log likelihood } \\
\text { at convergence }\end{array}$ & $-1,646.54$ & & \\
\hline
\end{tabular}

${ }^{a}$ Estimated cumulative normal distribution of the ratio of the mean and standard deviation (Hole, 2007). Note: ${ }^{*} P<0.10,{ }^{* *} P<0.05,{ }^{* * *} P<0.01$.

breeds. High Masculinity in bucks was highly preferred. Strong preferences for breeding stock with good Structure and Soundness was as expected because these animals are perceived to be stronger and healthier and are more likely to produce offspring with these same attributes. Producers showed strong preference for the Boer breed as compared with others, probably because Boer goats generally grow fast, are considered relatively easy to handle, and produce desirable carcass characteristics (Coffey, 2006).

The interpretation of the mixed logit coefficients involves estimation of the cumulative normal distribution of the ratio of the mean and standard deviation. In other words, it is estimated as $100^{*} \Phi\left(-b_{k} / s_{k}\right)$, where $\Phi$ is the cumulative standard normal distribution and $b_{k}$ and $s_{k}$ are the mean coefficient and standard deviation of the $k$ th attribute, respectively (Hole, 2007). The shares of producers preferring breeding bucks with high masculinity and good structure and soundness were $99 \%$ each, whereas $99 \%$ were negative toward $>2$-yearold animals. The percentages having negative preferences for Kiko and Spanish 
Table 4. Willingness to Pay (WTP) for Meat Goat Attributes

\begin{tabular}{lccr}
\hline \hline Buck Attributes & WTP $($ US\$) & \multicolumn{1}{c}{$95 \%$ Confidence Interval } \\
\hline Masculinity & $313.8^{* * *}(46.83)$ & 193.14 & 453.61 \\
Structure and soundness & $1,045.5^{* * *}(61.67)$ & 812.88 & $1,293.63$ \\
Age & $-511.2^{* * *}(53.03)$ & -517.70 & -478.25 \\
Kiko & $-617.8^{* * *}(97.81)$ & -698.67 & -484.27 \\
Boer & $129.3^{* *}(53.46)$ & 17.22 & 266.84 \\
Spanish & $-539.6^{* * *}(94.68)$ & -613.38 & -419.00 \\
Doe Attributes & & & \\
Femininity & $37.6(35.42)$ & 28.09 & 123.69 \\
Structure and soundness & $876.7^{* * *}(51.23)$ & 700.34 & $1,124.15$ \\
Age & $-248.2^{* * *}(35.68)$ & -276.61 & -216.56 \\
Kiko & $-311.8^{* * *}(68.52)$ & -394.54 & -210.94 \\
Boer & $143.2^{* * *}(44.55)$ & 48.03 & 269.73 \\
Spanish & $-275.1^{* * *}(64.09)$ & -349.43 & -184.33 \\
\hline \hline
\end{tabular}

Note: Standard errors in parentheses; ${ }^{*} P<0.10,{ }^{* *} P<0.05,{ }^{* * *} P<0.01$.

bucks were $73 \%$ and $88 \%$, respectively, whereas Boer bucks were preferred by $62 \%$ of respondents.

For does, 99\% preferred does with good structure and soundness, and $64 \%$ preferred Boer does. On the other hand, the shares not preferring $>2$-year-old, Kiko, and Spanish does were 99\%, 67\%, and 74\%, respectively. As expected, price had a negative sign, indicating that most of the producers $(96 \%)$ preferred animals with lower prices. Although the preference structures for both bucks and does were consistent, preference intensities varied slightly by gender, especially by breeds.

Table 4 shows producers' WTP for breeding stock attributes. Good structure and soundness was the most highly valued attribute at $\$ 1,046$ for bucks and $\$ 877$ for does, meaning that producers would be willing to pay this much more for animals with good as opposed to poor structure and soundness. To put this into perspective, the maximum prices included for bucks and does were $\$ 1,500$ and $\$ 1,250$, respectively, so clearly this attribute was of high importance to respondents-the differences in values between "good" and "poor" structure and soundness were more than two-thirds of the maximum prices we found advertised for both bucks and does. Producers considered Masculinity as the second most important attribute for bucks with a WTP value of \$314 for high- as opposed to low-masculinity bucks. Boer was the second most important attribute for does with a WTP value of \$143, and the third most important for bucks with a WTP value of $\$ 129$.

Age, Kiko, and Spanish had negative WTPs of $-\$ 511,-\$ 618$, and $-\$ 540$ for bucks, and $-\$ 248,-\$ 312$, and $-\$ 275$ for does, respectively, suggesting that producers would pay $\$ 511$ less for $>2$-year-old bucks than for $\leq 2$-year-old 
bucks, \$618 less for Kiko bucks than for other breeds, and so forth. Although there was a preference for Boer stock over the other breeds for both bucks and does, Coffey (2006) suggests that some producers are likely to use Boer bucks with Kiko does because the price of purebred Boer breeding stock could be significantly higher. This could be a cost-effective strategy, allowing for the production of desirable herd characteristics associated with both breeds. It could also be desirable from a breeding perspective to select for the hardy and parasiteresistant abilities of the Kiko and the growth and production abilities of the Boer goats.

\subsection{Results from Latent Class Models}

Tables 5 and 6 show results of the latent class models for bucks and does. The AIC and BIC values were minimized at four classes for the buck model, whereas for the doe model, the AIC was minimized at three classes and the BIC at four classes. Because the BIC values in the doe model were lowest at four classes and the AIC values for three and four classes were very close, four classes were selected. Results provide relatively few statistically significant class-specific variables. The sets of variables presented in this study represent probably the best possible groups of economically and theoretically important variables that led to convergence in the econometric analysis.

Larger-scale and younger producers (class 1) tended to have relatively stronger preferences for Boer bucks with high Masculinity and Structure and Soundness. The intensity of preference for Structure and Soundness was relatively higher as compared with that for other attributes. Producers who were larger-scale, sold higher percentages of goats for slaughter, and resided in the Southeast (class 3) tended to have relatively stronger preferences for bucks with high masculinity, good structure and soundness, and the Kiko breed. The striking difference in the preference results for class 3 was that the preference for the Kiko breed was positive in this class. A possible explanation for this result could be that the production conditions of the Southeast are relatively more favorable for Kiko goats because of their greater parasite resistance and lower incidence of hoof problems (Coffey, 2006; Wade, 2004).

Older producers holding bachelor's degrees (class 1) were more likely to prefer Kiko does with high femininity and good structure and soundness. Older producers holding bachelor's degrees and having lower percentages of their farm income derived from the goat enterprise (class 2) tended to prefer younger does with good structure and soundness, and Kiko and/or Spanish breeds. This class, however, represented a relatively small percentage $(7.4 \%)$ of the sample. On the other hand, producers selling lower percentages of their goats for slaughter and who were older (class 3) tended to prefer Boer does with good structure and soundness, whereas Femininity, Kiko, and Spanish attributes were less likely to be preferred. 
Table 5. Latent Class Model Run, Bucks

\begin{tabular}{|c|c|c|c|c|}
\hline & Class 1 & Class 2 & Class 3 & Class 4 \\
\hline Attributes & $\begin{array}{l}\text { Coefficient } \\
\text { (standard error) }\end{array}$ & $\begin{array}{l}\text { Coefficient } \\
\text { (standard error) }\end{array}$ & $\begin{array}{l}\text { Coefficient } \\
\text { (standard error) }\end{array}$ & $\begin{array}{l}\text { Coefficient } \\
\text { (standard error) }\end{array}$ \\
\hline Masculinity & $0.7501^{* * *}(0.2242)$ & $-17.4739(23.2682)$ & $1.3797^{* * *}(0.1848)$ & $13.5367^{* * *}(0.7650)$ \\
\hline Structure and soundness & $2.2415^{* * *}(0.2498)$ & $20.5851(33.2519)$ & $1.8076^{* * *}(0.1624)$ & $23.4343^{* * *}(1.3490)$ \\
\hline Age & $-0.5668^{* * *}(0.1761)$ & 4.1007 (20.2082) & $-1.1915^{* * *}(0.1787)$ & $-22.7791^{* * *}(0.8848)$ \\
\hline Kiko & $-0.3598(0.2558)$ & $-16.1233(44.2993)$ & $0.6623^{* * *}(0.2018)$ & $-14.1716^{* * *}(1.3695)$ \\
\hline Boer & $1.0275^{* * *}(0.2723)$ & $24.0258(33.6624)$ & $-1.3728^{* * *}(0.2417)$ & $-3.0420^{* * *}(0.5638)$ \\
\hline Spanish & $-0.7973^{* * *}(0.3156)$ & $-86.4243^{* *}(43.1975)$ & $-0.3779 *(0.2303)$ & $25.8677^{* * *}(11.4273)$ \\
\hline Price & $-0.0009^{* * *}(0.0002)$ & $-0.02624(0.0406)$ & $-0.0020^{* * *}(0.0002)$ & $-0.0433^{* * *}(0.0013)$ \\
\hline \multicolumn{5}{|l|}{ Class-Specific Parameters } \\
\hline Number Goats & $0.0068^{* *}(0.0032)$ & $-0.0022(0.0076)$ & $0.0060^{* *}(0.0031)$ & \\
\hline Percent Sale Slaughter & $-0.0050(0.0087)$ & $-0.0041(0.0101)$ & $0.0341^{* * *}(0.0069)$ & \\
\hline Bachelor & $0.2012(0.4491)$ & $-0.0796(0.6119)$ & $0.4018(0.4078)$ & \\
\hline Age & $-0.5006^{*}(0.2668)$ & $-0.3783(0.3491)$ & $0.1065(0.2376)$ & \\
\hline Farm Income Goat & $-0.1203(0.1350)$ & $-0.1429(0.1844)$ & $0.1469(0.1202)$ & \\
\hline Southeast & $-0.8317(0.7383)$ & $-0.2856(1.0321)$ & $1.6750^{* *}(0.7957)$ & \\
\hline Northeast & $0.8630(0.8536)$ & $0.1178(1.4191)$ & $0.0263(1.1443)$ & \\
\hline Midwest & $-0.0759(0.6226)$ & $0.0743(0.9850)$ & $0.8468(0.8008)$ & \\
\hline West & $-0.1282(0.8878)$ & $0.7961(1.1313)$ & $0.6975(1.0501)$ & \\
\hline Constant & $1.1059(1.1429)$ & $0.0929(1.5879)$ & $-4.0067^{* * *}(1.3845)$ & \\
\hline & & 0.068 & 0.398 & 0.331 \\
\hline \multicolumn{5}{|c|}{$\mathrm{AIC}_{\text {minimum(4) }}=2,841.34 ; \mathrm{BIC}_{\text {minimum (4) }}=2,783.06 ;$ log likelihood $=-1,225.64$} \\
\hline
\end{tabular}

Notes: Standard errors in parentheses; ${ }^{*} P<0.10,{ }^{* *} P<0.05,{ }^{* * *} P<0.01$. AIC, Akaike information criterion; BIC, Bayesian information criterion. 
Table 6. Latent Class Model Run, Does

\begin{tabular}{|c|c|c|c|c|}
\hline & Class 1 & Class 2 & Class 3 & Class 4 \\
\hline Attributes & $\begin{array}{l}\text { Coefficient } \\
\text { (standard error) }\end{array}$ & $\begin{array}{l}\text { Coefficient } \\
\text { (standard error) }\end{array}$ & $\begin{array}{l}\text { Coefficient } \\
\text { (standard error) }\end{array}$ & $\begin{array}{l}\text { Coefficient } \\
\text { (standard error) }\end{array}$ \\
\hline Femininity & $0.9780^{* * *}(0.2354)$ & $0.3336(0.4625)$ & $-5.1000^{* * *}(0.7867)$ & $0.2275(0.1970)$ \\
\hline Structure and soundness & $2.6543^{* * *}(0.2790)$ & $1.6554^{* *}(0.7162)$ & $7.1330^{* * *}(1.1344)$ & $2.3263^{* * *}(0.2436$ \\
\hline Age & $-1.1881^{* * *}(0.2455)$ & $1.8165^{* * *}(0.6884)$ & $0.1615(0.3916)$ & $-0.7479^{* * *}(0.1544$ \\
\hline Kiko & $0.8256^{* * *}(0.3177)$ & $4.5163^{* * *}(1.3307)$ & $-6.6625^{* * *}(0.9492)$ & $-0.6109^{* *}(0.2524)$ \\
\hline Boer & $-1.4359^{* * *}(0.3329)$ & $0.5935(0.5735)$ & $6.0692 * * *(0.9102)$ & $1.0215^{* * *}(0.2393$ \\
\hline Spanish & $0.1762(0.2874)$ & $2.7259^{* *}(1.3536)$ & $-4.0615^{* * *}(0.7389)$ & $-0.3210(0.2383)$ \\
\hline Price & $-0.0041^{* * *}(0.0004)$ & $-0.0000(0.0006)$ & $-0.0110^{* * *}(0.0018)$ & $-0.0011^{* * *}(0.0002$ \\
\hline \multicolumn{5}{|l|}{ Class-Specific Parameters } \\
\hline Number Goats & $-0.0021(0.0033)$ & $0.0002(0.0043)$ & $-0.0020(0.0030)$ & \\
\hline Percent Sale Slaughter & $0.0056(0.0064)$ & $0.0073(0.0086)$ & $-0.0103 *(0.0062)$ & \\
\hline Bachelor & $1.2284^{* * *}(0.4619)$ & $1.1423 *(0.6581)$ & $0.3247(0.4245)$ & \\
\hline Age & $0.8099^{* * *}(0.2715)$ & $0.7886^{* *}(0.4048)$ & $0.6753^{* * *}(0.2606)$ & \\
\hline Farm Income Goat & $-0.0044(0.1347)$ & $-0.4135^{*}(0.2430)$ & $0.0018(0.1211)$ & \\
\hline Southeast & $-0.1369(1.0092)$ & $0.0592(1.2087)$ & $-0.6703(1.0331)$ & \\
\hline Northeast & $14.6803(1,354.1180)$ & $15.1674(1,354.126)$ & $14.7929(1,354.117)$ & \\
\hline Midwest & $-0.5731(1.0020)$ & $-0.9656(1.2108)$ & $-0.5573(1.0037)$ & \\
\hline West & $-1.1133(1.2118)$ & $-53.9376(3,285.172)$ & $-0.6186(1.1915)$ & \\
\hline Constant & $-2.2582 * *(1.2143)$ & $-2.9871 *(1.5558)$ & $-0.6920(1.1845)$ & \\
\hline Class share & 0.358 & 0.074 & 0.325 & 0.244 \\
\hline \multicolumn{5}{|c|}{$\mathrm{AIC}_{\text {minimum(3) }}=3,137.63 ; \mathrm{AIC}_{(4)}=3,148.17 ; \mathrm{BIC}_{\text {minimum(4) }}=3,090.06 ; \log$ likelihood $=-1,383.11$} \\
\hline
\end{tabular}

Notes: Standard errors in parentheses; ${ }^{*} P<0.10,{ }^{* *} P<0.05,{ }^{* * *} P<0.01$. AIC, Akaike information criterion; BIC, Bayesian information criterion. 
Table 7. Top-Ranked Bucks and Does of Each Attribute Level

\begin{tabular}{llllll}
\hline \hline Ranking & $\begin{array}{l}\text { Masculinity (bucks)/ } \\
\text { Femininity (does) }\end{array}$ & $\begin{array}{l}\text { Structure and } \\
\text { Soundness }\end{array}$ & Age & Breed & Price \\
\hline Bucks & & & & & \\
1 & High & Good & $\leq 2$ Years & Boer & $\$ 300$ \\
2 & High & Good & $\leq 2$ Years & Others & $\$ 300$ \\
3 & Low & Good & $\leq 2$ Years & Boer & $\$ 300$ \\
4 & High & Good & $\leq 2$ Years & Boer & $\$ 700$ \\
6 & High & Good & $>2$ Years & Boer & $\$ 300$ \\
9 & High & Good & $\leq 2$ Years & Spanish & $\$ 300$ \\
11 & High & Good & $\leq 2$ Years & Kiko & $\$ 300$ \\
12 & High & Good & $\leq 2$ Years & Boer & $\$ 1,100$ \\
20 & High & Poor & $\leq 2$ Years & Boer & $\$ 300$ \\
27 & High & Good & $\leq 2$ Years & Boer & $\$ 1,500$ \\
Does & & Good & $\leq 2$ Years & Boer & $\$ 200$ \\
1 & High & Good & $\leq 2$ Years & Boer & $\$ 200$ \\
2 & Low & Good & $\leq 2$ Years & Others & $\$ 200$ \\
3 & High & Good & $>2$ Years & Boer & $\$ 200$ \\
5 & High & Good & $\leq 2$ Years & Boer & $\$ 550$ \\
7 & High & Good & $\leq 2$ Years & Spanish & $\$ 200$ \\
11 & High & Good & $\leq 2$ Years & Kiko & $\$ 200$ \\
13 & High & Good & $\leq 2$ Years & Boer & $\$ 900$ \\
21 & High & Poor & $\leq 2$ Years & Boer & $\$ 200$ \\
33 & High & Good & $\leq 2$ Years & Boer & $\$ 1,250$ \\
41 & High & & &
\end{tabular}

Note: These rankings are based on the relative willingness-to-pay estimates of each of the animal profiles. The highest-ranked profiles for each attribute level are indicated in bold.

Table 7 shows the ranking of animals based on the mixed logit estimates relative total values ${ }^{4}$ of WTP estimates of each of the animal profiles. Keep in mind that there are 128 possible animals being considered. Rather than including all 128 profiles, we include the highest-ranked profiles for each attribute level, which provides context on how low in the ranking one must go before an animal of a particular attribute level would be chosen. For example, the highest-ranked low-masculinity buck was ranked 3, whereas a poor structure-and-soundness buck and a $>2$-year-old buck were ranked at 20 and 6, respectively. The highestranked doe with poor structure and soundness was ranked 33.

\section{Discussion and Conclusions}

Because the quality of animals produced on a meat goat operation depends to a large degree on the breeding stock used, it is useful to identify the

4 The total values are estimated by summing up relative WTPs of each attribute for an animal profile. For example, the highest-ranked buck has a total value of $\$ 1,188.60$, which is a summation of WTPs of high masculinity $(\$ 313.80)$, good structure and soundness $(\$ 1,045.50), \leq 2$ years of age $(\$ 0)$, Boer breed $(\$ 129.30)$, and the price $(-\$ 300)$. 
most desirable characteristics of animals. Producers should consider these characteristics when selecting breeding stock, keeping in mind the relative costs of breeding stock and the market values of the resulting offspring. This study investigates producer preferences for meat goat breeding stock attributes using DCEs of U.S. meat goat producers. Five major attributes selected for the study were masculinity/femininity, structure and soundness, age, breed, and price. A mixed logit model with latent classes was used for the analysis.

Strong preferences were found for masculinity/femininity, structure and soundness, and the Boer breed. Older animals, Kiko and Spanish breeds, and higher purchase prices were generally less preferred. Almost all of the producers strongly considered masculinity, femininity and structure and soundness when purchasing breeding stock. The higher tendency to select animals with these attributes was expected because of their expected higher production potential and strong physical qualities that could be transferred to offspring. Although the Boer breed was almost equally preferred for both bucks and does, the share of the population that did not prefer Kiko and Spanish goats was smaller for does, indicating that more producers would purchase a Kiko/Spanish doe as compared with a Kiko/Spanish buck. One of the reasons for this could be that producers may choose to use a Boer buck for multiple Kiko and Spanish does so as to reduce the cost of production-as breeding Boer goats are considered relatively more expensive than others, and crosses can still produce goats with Boer qualities (i.e., muscular kids with red heads).

WTP estimates showed that meat goat breeding stock attributes were preferred in the order of structure and soundness, masculinity, Boer, age, Spanish, and Kiko. The highest-ranked bucks and does had similar attribute levels: high masculinity or femininity, good structure and soundness, $\leq 2$ years of age, Boer breed, and lowest price. Results showed that preference differed according to farm characteristics, producer demographics, and location of the farm. Further explaining the mixed logit results, the latent class model results showed that there was a stronger preference for Kiko and Spanish goats among the slaughter goat producers as compared with breeders and show goat producers, whereas the preference for masculinity/femininity and structure and soundness remained positive for all classes. Overall, the results provide strong evidence of heterogeneity in producer selection of meat goat breeding stock. The meat goat industry could benefit by considering the types of breed preferred in certain production systems and the suitability of production region for those breeds.

\section{References}

Boxall, P.C., and W.L. Adamowicz. "Understanding Heterogeneous Preferences in Random Utility Models: A Latent Class Approach.” Environmental and Resource Economics 23,4(2002):421-46. 
Cameron, T.C., and J. Englin. "Respondent Experience and Contingent Valuation of Environmental Goods." Journal of Environmental Economics and Management 33,3(1997):296-313.

Casey, N.H., and E.C. Webb. "Managing Goat Production for Meat Quality.” Small Ruminant Research 89,2-3(2010):218-24.

Coffey, L. "General Overview (Do You Want to Be a Goat Producer?).” Meat Goat Production Handbook. Langston, OK: E (Kika) de la Garza American Institute for Goat Research, Langston University, 2006, pp. 1-12.

Dillman, D., J.D. Smyth, and L.M. Christian. Internet, Mail, and Mixed-mode Surveys: The Tailored Design Method. 3rd ed. New York: John Wiley and Sons, 2009.

Greene, W.H. Econometric Analysis. 6th ed. Upper Saddle River, NJ: Pearson Prentice-Hall, 2008.

Greene, W.H., and D.A. Hensher. "A Latent Class Model for Discrete Choice Analysis: Contrasts with Mixed Logit." Transportation Research Part B: Methodological 37,8(2003):681-98.

Hole, A.R. "Fitting Mixed Logit Models by Using Maximum Simulated Likelihood." Stata Journal 7,3(2007):388-401.

Kuhfeld, W.F., R.D. Tobias, and M. Garratt. "Efficient Experimental Design with Marketing Research Applications." Marketing Research Methods in SAS, W.F. Kuhfeld, ed. Cary, NC: SAS Institute Inc., 2010, pp. 243-65. Internet site: http://support.sas.com/techsup/ technote/mr2010d.pdf (Accessed February 8, 2013).

Louviere, J.J., T.N. Flynn, and R.T. Carson. "Discrete Choice Experiments Are Not Conjoint Analysis.” Journal of Choice Modelling 3,3(2010):57-72.

Ouma, E., A. Abdulai, and A. Drucker. "Measuring Heterogeneous Preferences for Cattle Traits among Cattle-Keeping Households in East Africa." American Journal of Agricultural Economics 89,4(2007):1005-19.

Pacifico, D., and H.I. Yoo. "Iclogit: A Stata Module for Estimating Latent Class Conditional Logit Models via the Expectation-Maximization Algorithm" Australian School of Business Research Paper No. 2012 ECON 49. Kensington, NSW, Australia: School of Economics, University of South Wales, 2012. Internet site: http://ssrn.com/abstract= 2174146 (Accessed November 23, 2012).

Pew Research Center. "U.S. Foreign-Born Population Trends." Modern Immigration Wave Brings 59 Million to U.S., Driving Population Growth and Change through 2065. Washington, DC: Pew Research Center, 2015, pp. 65-76. Internet site: http://www. pewhispanic.org/files/2015/09/2015-09-28_modern-immigration-wave_REPORT.pdf (Accessed November 15, 2016).

Ruto, E., G. Garrod, and R. Scarpa. "Valuing Animal Genetic Resources: A Choice Modeling Application to Indigenous Cattle in Kenya." Agricultural Economics 38,1(2008):89-98.

Salomon, I., and M. Ben-Akiva. "The Use of the Life-Style Concept in Travel Demand Models." Environmental and Planning A 15,5(1983):623-38.

Shurley, M., and F. Craddock. "U.S. Meat Goat Industry: Past, Present, and Future." Presentation at the Gathering of Goat Producers IV, Seguin, Texas, July 2005. Internet site: http://theikga.org/us_meat_goat_industry.html (Accessed November 15, 2016).

Stanton, T. 2012. “An Overview of the Goat Meat Market 2012.” Ithaca, NY: Sheep \& Goat Marketing, Cornell University, 2012. Internet site: http://sheepgoatmarketing.info/ education/meatgoatmarket.php (Accessed January 8, 2014). 
Sy, H.A., M.D. Faminow, G.V. Johnson, and G. Crow. "Estimating the Values of Cattle Characteristics Using an Ordered Probit Model." American Journal of Agricultural Economics 79,2(1997):463-76.

Tano, K., M. Kamuanga, M.D. Faminow, and B. Swallow. "Using Conjoint Analysis to Estimate Farmer's Preferences for Cattle Traits in West Africa." Ecological Economics 45,3(2003):393-407.

Train, K.E. Discrete Choice Methods with Simulation. Cambridge: Cambridge University Press, 2009.

. "Halton Sequences for Mixed Logit." Working paper no. 278, Berkeley: Department of Economics, University of California, Berkeley, 2000.

U.S. Department of Agriculture, Animal and Plant Health Inspection Service, Veterinary Services (USDA-APHIS-VS). "The Goat Industry: Structure, Concentration, Demand, and Growth.” Riverdale, MD: USDA-APHIS, 2005. Internet site: http://www.aphis. usda.gov/animal_health/emergingissues/downloads/goatreport090805.pdf (Accessed January 28, 2013).

- Small-Scale U.S. Goat Operations. Riverdale, MD: USDA-APHIS, 2011. Internet site: http://www.aphis.usda.gov/animal_health/nahms/smallscale/downloads/ Small-scale_goat.pdf (Accessed December 7, 2012).

U.S. Department of Agriculture, National Agricultural Statistics Service (USDA-NASS). 2007 Census of Agriculture: United States Summary and State Data. Vol 1, Geographic Area Series, Part 51. Washington, DC: USDA-NASS, 2009. Internet site: http://www.agcensus. usda.gov/Publications/2007/Full_Report/usv1.pdf (Accessed January 15, 2014).

- 2012 Census of Agriculture: United States Summary and State Data. Vol 1, Geographic Area Series, Part 51. Washington, DC: USDA-NASS, 2014. Internet site: http://www.agcensus.usda.gov/Publications/2012/Full_Report/Volume_1, Chapter_1_US/usv1.pdf (Accessed October 30, 2016).

Wade, M. "Kiko Goats in the USA." Rare Breeds NewZ 66(August 2004). Internet site: http:// www.rarebreeds.co.nz/kikoa.html (Accessed November 15, 2016).

\section{Appendix A}

Example of Choice for Buck

\begin{tabular}{lll}
\hline \hline Attributes & Buck A & Buck B \\
\hline Masculinity & High & Low \\
Structure and soundness & Good & Poor \\
Age & $\leq 2$ Years & $\leq 2$ Years \\
Breed & Spanish & Kiko \\
Price & $\$ 1,500$ & $\$ 700$ \\
\hline \hline
\end{tabular}

Which buck would you buy if these were the only bucks available in the marketplace?

$\square$ Buck A $\quad \square$ Buck B $\quad \square$ Neither 
Example of Choice for Doe

\begin{tabular}{lll}
\hline \hline Attributes & Doe A & Doe B \\
\hline Femininity & High & Low \\
Structure and soundness & Good & Poor \\
Age & $\leq 2$ Years & $\leq 2$ Years \\
Breed & Spanish & Kiko \\
Price & $\$ 1,250$ & $\$ 550$ \\
\hline \hline
\end{tabular}

Which doe would you buy if these were the only does available in the marketplace? $\square$ Doe A $\square$ Doe B $\quad \square$ Neither 